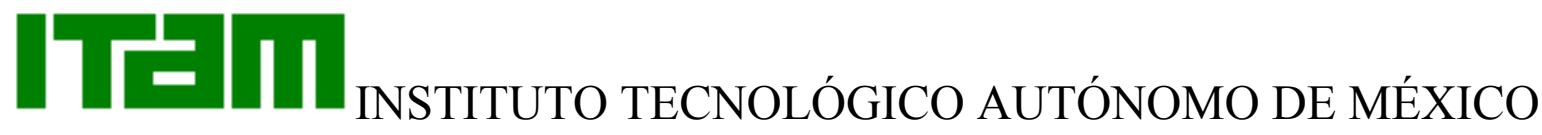

\section{CENTRO DE INVESTIGACIÓN ECONÓMICA}

\section{Discussion Paper Series}

Deception and Misreporting in a Social Program

César Martinelli

Instituto Tecnológico Autónomo de México

\author{
and \\ Susan W. Parker \\ CIDE
}

June 2006

Discussion Paper 06-02

Av. Camino a Santa Teresa \# 930

Col. Héroes de Padierna

México, D.F. 10700

$\mathrm{M}$ E X I C O 


\title{
Deception and Misreporting in a Social Program
}

\author{
César Martinelli and Susan W. Parker* \\ First Version: June 2006 \\ This Version: September 2006
}

\begin{abstract}
We investigate empirically the extent of misreporting in a povertyalleviation program in which self-reported information, followed by a household visit, is used to determine eligibility. In the model we propose and estimate, underreporting may be due to a deception motive, and overreporting to an embarrassment motive. We find that underreporting of goods and desirable home characteristics is widespread, and that overreporting is common with respect to goods linked to social status. Larger program benefits encourage underreporting and discourage overreporting. The effect of benefits on underreporting is significant under a variety of specifications. We also estimate the relative costs of lying and embarrassment for different goods.
\end{abstract}

*Martinelli: Centro de Investigación Económica, Instituto Tecnológico Autónomo de México, Camino Santa Teresa 930, 10700 México DF (martinel@itam.mx); Parker: División de Economía, Centro de Investigación y Docencia Económicas, Carretera MéxicoToluca 3655, 01210 México DF (susan.parker@cide.edu). Iliana Yaschine, Citlalli Hernández and Alejandra Macías of Oportunidades generously provided assistance with the data and questions on program operation. 


\section{Introduction}

Targeted poverty-alleviation programs rely on the ability to identify the poor population from the non-poor. The costs of identifying the poor are presumably larger in developing countries, where variables such as income cannot be independently verified (for example through tax institutions). As a consequence, targeted programs in developing countries usually rely on information provided by the applicants. It is widely believed that the incentives for underreporting of economic conditions in this context are quite large. Nevertheless, to our knowledge, no previous research has analyzed the extent to which individuals misreport their characteristics when applying for social programs. This lack of research is because the data requirements are severe, e.g. information is needed on what an individual reports to a government agency when applying for a program, as well as independent information on the "true" characteristics of the individual. Such information has been rarely, if at all, available. In this paper, we employ a very unusual database from Oportunidades, the Mexican government main poverty-alleviation scheme, to explore quantitatively the extent and causes of misreporting in social programs.

Economists usually assume that individuals tell the truth only if this is incentive-compatible given the material outcomes. According to conventional assumptions, applicants to a social program will understate their material possessions, so long as this increases the probability of benefitting from the program. A corollary of this view is that underreporting should be made costly by the program requirements. ${ }^{1}$ If underreporting is not costly, we can expect potential beneficiaries to display a strategic bias toward deception. Ethical considerations may act as a counterweight, ${ }^{2}$ however, so that the willingness of individuals to deceive for advantage is worth exploring quantitatively.

Research in participation in welfare programs reminds us that very often individuals do not apply to a program even if participation seems convenient given the material outcomes. This has been interpreted by Moffitt (1983) and others as the result of a social "stigma" or utility loss associated with par-

\footnotetext{
${ }^{1}$ See e.g. Besley and Coate $(1992,1995)$.

${ }^{2}$ See Bok (1999) for a thoughtful review of the positions of moral philosophers about deception, and the recent article by Gneezy (2005) for some experimental evidence.
} 
ticipation. ${ }^{3}$ By analogy, we may expect that even some individuals who are willing to apply may have a bias toward overreporting due to embarrassment or stigma associated with the lack of certain material goods.

We use a database from the Mexican program Oportunidades to estimate a model of reporting in the context of social programs that encompasses both deception and embarrassment considerations. When this program was introduced in urban localities in 2002, an advertising campaign was carried out to inform potential applicants that registration centers for the program would open during certain dates. Applicants who turned up at the registration centers were asked to provide information on their address and on their household characteristics. Eligibility into the program was determined using the household characteristics to compute a household poverty index. ${ }^{4}$ Applicants initially found to be eligible received a household visit during the coming weeks to verify the information given, after which a final classification on eligibility was made.

Our database is rather unique in that it includes not only what individuals reported at the registration center but also what they were actually found to have during the household visit for over a million households. Thus, we can check whether applicants reported correctly, understated or overstated their possessions in answering the questionnaire. Since we can calculate the benefits for each applicant according to program rules, we have information about what was at stake for each applicant.

We find that underreporting is widespread in every item we investigate. Overreporting is common in goods that may have a "status" value. Both underreporting and overreporting are clearly sensitive to material incentives. Larger program benefits encourage underreporting and discourage overreporting. Quantitatively speaking, though, the impact of program benefits on misreporting is not overwhelming at the margin. As an illustration, increasing in $50 \%$ the monetary benefits from the program (which were close to $26 \%$

\footnotetext{
${ }^{3}$ Riphahn (2001) provides some recent evidence on widespread lack of participation in social programs by potential beneficiaries. See also Currie (2004) for a review of the literature on take up.

${ }^{4}$ The weights attached to each answer in the household poverty index were previously determined using a poverty regression similar to the methodology described by Ravallion (1996). The general methodology was public (Reglas de Operación 2002) but not the specific weights.
} 
of the households' preprogram expenditure) would increase underreporting in a few percentage points, and would have an even smaller impact in deterring overreporting. There is also evidence that there are forces at work other than material incentives in the decision to misreport or report accurately. For instance, education discourages underreporting and, very clearly, encourages overreporting. This is interesting because education may be linked to socialization and therefore to sensitivity to status considerations. Finally, male applicants underreport more and overreport less than female applicants with respect to "status" goods.

The results suggest that the use of self-reported household characteristics in targeting poverty-alleviation programs can be improved upon by taking into account both under and overreporting in the allocation of weights to household characteristics. For instance, the eligibility index employed by Oportunidades officials gave some weight to gas boilers, cars, trucks, and washing machines, all items for which underreporting was rampant. The index also gave weight to toilets, tap water, and concrete floor, items for which overreporting was common. While underreporting may have been corrected at the household visit stage, overreporting is worrisome because it may have led to the exclusion of the program of households that could qualify in principle. It is also a problem that is harder to deal with: If a poverty index accurately identifies goods whose absence is a clear indicator of poverty, it is also probably identifying goods associated with a higher social status.

At a broader level, there has recently been a surge of interest by economists on the issue of deception in a variety of contexts. ${ }^{5}$ The experimental work of Gneezy (2005) shows that in two-party interactions people care both about their own gains and about the losses to the other party in deciding whether to deceive. Other experimental studies reviewed by Croson (2005) reveal that deception is widespread and that generally individuals are not sufficiently skeptical of statements they receive from others. Our setup is different in that individuals' deceptive behavior does not create losses for another easily identified individual. Our results on the limited willingness to deceive may be of particular interest given the high stakes involved for applicants in our database.

\footnotetext{
${ }^{5}$ Including among others Crawford (2003), Chen (2005), Ettinger and Jehiel (2006), and Kartik, Ottaviani and Squintani (2006).
} 
Overreporting may be due at least in part to inaccurate beliefs similar to the overconfidence or "self-serving bias" described by Babcock and Loewenstein (1997) in other contexts. Overreporters may feel better about themselves by believing that their house floor is accurately described as mostly covered by concrete rather than dirt, even if an "impartial" observer, such as the visitor sent by the program, may disagree.

\section{Evidence on Misreporting}

Table I provides evidence on misreporting in Oportunidades from a random sample of 101,803 applicants (10\% of the applicants interviewed at the registration centers in 2002). Out of this sample, 74,034 applicants initially qualified and received a household verification visit. We have calculated under and overreporting as follows. For each of the goods or desirable household characteristics $g$, let $A_{g}$ be the set of applicants who asserted having the good at the registration center interview, and let $D_{g}$ be the set of applicants who denied having the good at the interview. Similarly, let $H_{g}$ be the set of applicants who were found to have the good at the household visit, and let $N_{g}$ be the set of applicants who were found not to have the good at the household visit. We define

$$
\begin{gathered}
\text { underreporting of good } g=\frac{\left|D_{g} \cap H_{g}\right|}{\left|H_{g}\right|} \times 100 \text {, and } \\
\text { overreporting of good } g=\frac{\left|A_{g} \cap N_{g}\right|}{\left|N_{g}\right|} \times 100 \text {. }
\end{gathered}
$$

Underreporting is substantial for every item described in Table I. Since there are a few goods, such as cars, trucks, phones and video recorders, that may have been hidden during the household visit, we may be understating the already high incidence of underreporting for these goods. Other items seem much harder to hide.

Overreporting is substantial only for a few items in Table I, including toilets, tap water, gas stoves, and concrete floor. This list suggests that applicants may have been embarrassed to report the lack of these items, or perhaps unwilling to acknowledge their true household characteristics. Toilets, tap water, and concrete floor are widespread among the urban poor in our sample, and lacking some of these may carry a stigma. 
TABLE I

MisReporting in OpoRTUNIDADES ${ }^{a}$

\begin{tabular}{lccc}
\hline \hline Good & $\begin{array}{c}\text { Underreporting } \\
\text { (as \% of Households } \\
\text { Having Good) }\end{array}$ & $\begin{array}{c}\text { Overreporting } \\
\text { (as \% of Households } \\
\text { Not Having Good) }\end{array}$ & $\begin{array}{c}\text { Households } \\
\text { Having Good } \\
\text { (as \% of Total) }\end{array}$ \\
\hline Concrete Floor & 14.45 & 25.41 & 64.25 \\
Tap Water & 13.79 & 31.76 & 70.27 \\
Toilet & 16.58 & 39.07 & 73.08 \\
Gas Boiler & 73.12 & 1.07 & 3.22 \\
Washing Machine & 53.46 & 6.20 & 8.49 \\
Phone & 73.12 & 1.34 & 2.64 \\
Car & 83.10 & 0.80 & 1.54 \\
Truck & 81.71 & 0.61 & 1.53 \\
Satellite TV & 73.91 & 1.74 & 2.32 \\
Water Tank & 58.44 & 3.80 & 5.18 \\
Refrigerator & 36.93 & 12.05 & 27.07 \\
Gas Stove & 24.25 & 28.56 & 48.40 \\
Video Recorder & 79.73 & 1.98 & 3.25 \\
\hline
\end{tabular}

${ }^{a}$ Observations: 74034. Source: ENCASURB. 
The incentive to lie to participate in the program has been substantial; the average monthly cash benefit of participation for urban households is about $26.4 \%$ of the average applicant's household pre-program expenditure in our sample. Cash benefits for participants in Oportunidades include a purely unconditional grant (termed "nutrition grant"), plus some grants conditional on the school attendance of the children in the household, as described in Table II. The program also includes free medical consultations and nutrition supplements. ${ }^{6}$ Since we can calculate the potential cash benefits a household can receive under the program, we have an idea about the incentive to underreport (or the disincentive to overreport) for each applicant. Table III provides some additional information on the applicants and their households. Most applicants are women, which is consistent with the fact that the transfers under the program are paid to the mother of the household.

Our data source is the ENCASURB (Encuesta Socio-Económica de los Hogares Urbanos), the survey used to establish eligibility for Oportunidades for urban households. The ENCASURB consists of three related questionnaires. The first is the "inclusion questionnaire" which was applied to applicants at the registration center. Applicants were informed whether they qualify or not on the spot. Applicants who qualified for a household visit, and a large fraction of those who did not, were asked to answer a second questionnaire about themselves and their households. Finally, applicants who were initially declared eligible were informed that they would receive a household visit in the next two or three weeks. A "verification questionnaire" (similar to the inclusion questionnaire) was applied during the household visit. Applicants were required to let interviewers into their households to visually inspect their belongings. Table I employs the answers to the first and third questionnaire, and Table III the answers to the second.

There are a couple of potential selection issues in relation to our data. We study the reporting of only those individuals who apply, whereas it is commonly the case that many eligible households do not apply to targeted social programs. In addition, not all households who apply were verified

\footnotetext{
${ }^{6}$ There has been a good deal of research estimating the impact of program benefits on participating households in rural areas in terms of education and health, including Schultz (2004), Behrman, Sengupta and Todd (2005), Gertler (2004), and Todd and Wolpin (2004), among others. None of those papers, however, has dealt with the issues raised by the selection of beneficiaries in urban areas which are the focus of this paper.
} 
TABLE II

Monthly Cash Benefits of Oportunidades ${ }^{a}$

\begin{tabular}{|c|c|c|c|c|}
\hline \multirow[t]{12}{*}{ Grants } & \multicolumn{2}{|l|}{ Nutrition Grant } & \multicolumn{2}{|c|}{150} \\
\hline & Education Grants: & Grade & Boys & Girls \\
\hline & \multirow[t]{4}{*}{ Primary } & 3 & 100 & 100 \\
\hline & & 4 & 115 & 115 \\
\hline & & 5 & 150 & 150 \\
\hline & & 6 & 200 & 200 \\
\hline & \multirow[t]{3}{*}{ Middle School } & 7 & 290 & 310 \\
\hline & & 8 & 310 & 340 \\
\hline & & 9 & 325 & 375 \\
\hline & \multirow{3}{*}{ High School } & 10 & 490 & 565 \\
\hline & & 11 & 525 & 600 \\
\hline & & 12 & 555 & 635 \\
\hline \multirow{2}{*}{$\begin{array}{l}\text { Maximum Transfer } \\
\text { to Household }\end{array}$} & With High-School Children & & \multicolumn{2}{|c|}{1550} \\
\hline & Other Households & & \multicolumn{2}{|c|}{915} \\
\hline Average Transfer $b$ & & & \multicolumn{2}{|c|}{350} \\
\hline
\end{tabular}

${ }^{a}$ In Mexican pesos (2002); 11 pesos is approx. US $\$ 1 .{ }^{b}$ Urban households (2003).

TABLE III

Applicants And their Households ${ }^{a}$

\begin{tabular}{lrrrrr}
\hline \hline & \multicolumn{2}{c}{ Verified Group } & & \multicolumn{2}{c}{ Not Verified Group } \\
\cline { 2 - 3 } \cline { 6 - 6 } Household Characteristics & Mean & Std. Dev. & & Mean & Std. Dev. \\
\hline Total Monthly Expenditure (pesos) & 1312 & 766 & & 1405 & 735 \\
Per Capita Expenditure (pesos) & 319 & 193 & & 382 & 219 \\
Family Size & 4.54 & 1.93 & & 4.05 & 1.73 \\
Children from 0 to 5 & 0.77 & 0.87 & & 0.49 & 0.71 \\
Children from 6 to 21 & 1.90 & 1.54 & & 1.63 & 1.37 \\
& & & & & \\
Applicant Characteristics & Mean & Std. Dev. & & Mean & Std. Dev. \\
\hline Gender (Female=1) & 0.94 & 0.23 & & 0.94 & 0.24 \\
Age & 38.21 & 14.46 & & 40.47 & 14.43 \\
Education & 4.44 & 3.39 & & 5.05 & 3.49 \\
Working & 0.27 & 0.44 & & 0.27 & 0.44 \\
Married & 0.47 & 0.50 & & 0.50 & 0.50 \\
Cohabitating & 0.22 & 0.42 & & 0.16 & 0.36 \\
Look very poor to interviewer & 0.37 & 0.48 & & 0.24 & 0.43 \\
\hline
\end{tabular}

${ }^{a}$ Observations: 74034 verified and 10424 not verified applicants. Source: ENCASURB. 
and this is likely directly related to their reporting. While most individuals are initially declared eligible, note that underreporting can only increase the likelihood of being declared eligible at the module whereas overreporting can reduce the likelihood. Thus, in our sample of verified individuals, ceteris paribus, we are more likely to have underreporters than overreporters. This is of course important not only for potential selection, but for the implication that those who overreport may not receive benefits precisely because of their overreporting. ${ }^{7}$

In the next section, we model the decision about reporting of an applicant who understands that these reports are used to determine whether her household qualifies or not for a social program.

\section{$3 \quad$ Misreporting and Incentives}

Consider an applicant to a social program who is asked to answer a questionnaire about whether the applicant's household has or not some goods or desirable characteristics (e.g. phone, tap water, concrete floor, etc.). Denoting applicants by $a=1, \ldots, n$ and goods by $g=1, \ldots, m$, the report of applicant $a$ is a vector $\left(r_{a g}\right)_{g=1}^{m} \in\{0,1\}^{m}$, where $r_{a g}=1$ means "yes" and $r_{a g}=0$ means "no." In answering the questionnaire, applicant $a$ is aware of the true answers to the questions, which are represented by $\left(t_{a g}\right)_{g=1}^{m} \in\{0,1\}^{m}$. We say that applicant $a$ overreports, underreports or reports truthfully with regard to good $g$ if $r_{a g}>t_{a g}, r_{a g}<t_{a g}$, or $r_{a g}=t_{a g}$, respectively.

Eligibility into the program is determined in the following manner. There is a vector of weights assigned to each good $\left(\omega_{g}\right)_{g=1}^{m} \in \Re_{+}^{m}$, and a cutoff $\rho \geq 0$ (the "poverty line"). With probability $1-\delta$, the applicant is eligible for the program if $\sum_{g} \omega_{g} r_{a g} \leq \rho$. With probability $\delta$, the applicant is eligible if $\sum_{g} \omega_{g} r_{a g}+\sum_{g} \tau_{g}\left(t_{a g}-r_{a g}\right)^{+} \leq \rho$. Here, $\delta$ represents the probability that there is some effective monitoring of the applicant's household goods, and $\tau_{g}$ represents the penalty the applicant expects to receive for underreporting with respect to good $g$ if monitoring turns out to be effective. ${ }^{8}$ If the appli-

\footnotetext{
${ }^{7}$ We are studying the application decision in related work. In a sample of poor urban areas approximately 65 percent of eligible households applied to the program. Of those not applying, 84 percent can be attributed to lack of knowledge of the program or the lack of a registration module in the vicinity.

${ }^{8}$ Applicants may have believed that either there was not going to be a verification visit
} 
cant expects that effective verification will result at least in the correction of underreporting, we would have $\tau_{g} \geq \omega_{g}{ }^{9}$

We assume that applicants hold point beliefs about the vectors $\left(\varpi_{g}\right)_{g=1}^{m}$ and $\left(\tau_{g}\right)_{g=1}^{m}$. We also assume that applicants believe that $\rho$ is uniformly distributed in some interval $(0, \bar{\rho})$ where $\bar{\rho} \geq \sum_{g} \max \left\{\omega_{g}, \tau_{g}\right\}$. Thus, according to the applicant's beliefs, the probability that $a$ is eligible is ${ }^{10}$

$$
\begin{aligned}
P\left(r_{a g}, t_{a g}\right) \equiv(1-\delta)\left(1-\sum_{g} w_{g} r_{a g}\right) & +\delta\left(1-\sum_{g} w_{g} r_{a g}-\sum_{g} p_{g}\left(t_{a g}-r_{a g}\right)^{+}\right) \\
= & 1-\sum_{g} w_{g} r_{a g}-\delta \sum_{g} p_{g}\left(t_{a g}-r_{a g}\right)^{+},
\end{aligned}
$$

where $w_{g} \equiv \omega_{g} / \bar{\rho}$ and $p_{g} \equiv \tau_{g} / \bar{\rho}$.

Let $U(\cdot)$ be the indirect utility function of applicant $a$, let $Y_{a}$ be her preprogram income and let $B_{a}$ be the monetary benefits of participating in the program. The utility gain of being eligible for the program is then

$$
\Delta U\left(Y_{a}, B_{a}\right) \equiv U\left(Y_{a}+B_{a}\right)-U\left(Y_{a}\right) .
$$

Finally, let $c_{a g}$ be the utility cost of "concealing" good $g$ or at least trying to do so, which is suffered by applicant $a$ whenever she underreports, and let $e_{a g}$ be the utility cost of "embarrassment" with respect to good $g$, which is suffered by applicant $a$ whenever reporting truthfully not having the good.

The problem of applicant $a$ is then

$$
\max _{\left(r_{a g}\right)_{g=1}^{m}}\left(P\left(r_{a g}, t_{a g}\right) \Delta U\left(Y_{a}, B_{a}\right)-\sum_{g} c_{a g}\left(t_{a g}-r_{a g}\right)^{+}-\sum_{g} e_{a g}\left(1-r_{a g}-t_{a g}\right)^{+}\right) .
$$

From the solution to this problem, the applicant will underreport about good $g$ if $t_{a g}=1$ and

$$
\left(w_{g}-\gamma p_{g}\right) \Delta U\left(Y_{a}, B_{a}\right)-c_{a g} \geq 0,
$$

with some probability, or that interviewers would not be careful. These beliefs, of course, may turn out to be incorrect ex post.

${ }^{9}$ Program operating rules state that "Program benefits will be suspended permanently when the family has given false information with respect to their socioeconomic conditions" (Reglas de Operación 2002). Interviewers were not instructed to inform applicants about this program rule, though. As discussed later on, apparently there was no penalty other than the correction of underreporting.

${ }^{10}$ Note that the probability of being eligible is additively separable in the reports about the different goods. Separability follows from the assumption of uniform beliefs about the cutoff for eligibility into the program, and it is useful in terms of estimating the model. 
and will overreport about good $g$ if $t_{a g}=0$ and

$$
-w_{g} \Delta U\left(Y_{a}, B_{a}\right)+e_{a g} \geq 0
$$

We assume that applicants have a constant relative risk aversion utility function with risk parameter $\sigma$; that is ${ }^{11}$

$$
\Delta U\left(Y_{a}, B_{a}\right)= \begin{cases}\left(Y_{a}+B_{a}\right)^{1-\sigma} /(1-\sigma)-Y_{a}^{1-\sigma} /(1-\sigma) & \text { if } \sigma \neq 1 \\ \ln \left(Y_{a}+B_{a}\right)-\ln Y_{a} & \text { if } \sigma=1\end{cases}
$$

We assume further that $c_{g a}$ and $e_{g a}$ depend linearly on a vector of observable applicant characteristics $X_{a}$ and a random term; that is

$$
c_{a g}=\alpha_{c g}+\gamma_{c g} X_{a}+\epsilon_{c a g} \quad \text { and } \quad e_{a g}=\alpha_{e g}+\gamma_{e g} X_{a}+\epsilon_{e a g}
$$

where $\epsilon_{1 a g}$ and $\epsilon_{2 a g}$ are random terms independently distributed across goods and across people according to logistic distributions with location parameter 0 and scale parameter $s_{1 g}$ and $s_{2 g}$, respectively.

Thus, applicant $a$ will underreport about good $g$ if $t_{a g}=1$ and

$$
\alpha_{1 g}+\beta_{1 g} \Delta U\left(Y_{a}, B_{a}\right)+\gamma_{1 g} X_{a} \geq \epsilon_{1 a g}
$$

and will overreport about good $g$ if $t_{a g}=0$ and

$$
\alpha_{2 g}+\beta_{2 g} \Delta U\left(Y_{a}, B_{a}\right)+\gamma_{2 g} X_{a} \geq \epsilon_{2 a g},
$$

where $\alpha_{1 g}=-\alpha_{c g} / s_{1 g}, \beta_{1 g}=\left(w_{g}-\delta p_{g}\right) / s_{1 g}, \gamma_{1 g}=-\gamma_{c g} / s_{1 g}, \epsilon_{1 a g}=\epsilon_{c a g} / s_{1 g}$, $\alpha_{2 g}=\alpha_{e g} / s_{2 g}, \beta_{2 g}=-w_{g} / s_{2 g}, \gamma_{2 g}=\gamma_{e g} / s_{2 g}$ and $\epsilon_{2 a g}=-\epsilon_{e a g} / s_{2 g}$. Note that the error terms have a standard logistic distribution. Under the assumption that household visits were in fact effective in monitoring misreporting, equations (1) and (2) can then be estimated using logistic regressions.

\footnotetext{
${ }^{11}$ We are sidestepping for simplicity the issue of the different horizon of benefits for different applicants, according to the age and school grade of their children. If household $a$ has a horizon of benefits $T_{a}$ and discount factor $\beta_{a}$, then its expected benefit of participating should be multiplied by $\left(1-\beta_{a}^{T_{a}+1}\right) /\left(1-\beta_{a}\right)$. If this term is similar for all applicants (e.g. they all discount the future heavily) ignoring it is just a normalization of the utility function.
} 


\section{Empirical Analysis}

We have estimated equations (1) and (2) for different values of the riskaversion coefficient using the data from ENCASURB. We take $Y_{a}$ to be the expenditure per capita in the household of the applicant, as reported in the second questionnaire, and $B_{a}$ to be the cash benefit from the program for the household in per capita terms, calculated using the structure of program benefits and the age and schooling levels of household members. By the time the information on expenditure was collected, applicants knew that they qualified for the program and knew also that reported expenditure was not among the criteria for participation in the program. Nevertheless, we may think that a person that under or overreported with respect to goods may be inclined to do the same with respect to expenditure. We thus include among our estimations the case of risk-neutrality $(\sigma=0)$, in which the utility gain of participating is just the benefits from the program for the household in per capita terms.

The independent variables included in the regressions, other than the utility gain $\Delta U\left(Y_{a}, B_{a}\right)$, are age of the applicant, years of education, gender, whether the applicant works outside his or her house, whether the applicant speaks an indigenous language, per capita expenditure in the applicant's household, and a set of dummies reflecting subjective judgements of the interviewer: whether the applicant looks "very poor," "somewhat poor," or "not poor," and whether the applicant seems to understand the questionnaire. ${ }^{12}$ We also include registration center fixed effects, in an attempt to deal with unobserved heterogeneity both in who attends different registration centers and in treatment of applicants across centers.

\subsection{Utility Gains and Applicants' Beliefs}

Table IV provides maximum likelihood estimates of $\beta_{1 g}$ and $\beta_{2 g}$ for different goods, using as samples respectively those households who were found to have the good and those households who were not. Estimates in Table IV

\footnotetext{
${ }^{12}$ Interviewers were also asked if they thought the applicants were lying. Consistent with the evidence that individuals are bad at detecting the deception of others (Croson 2005), interviewers answered that they thought they were told the truth in $98.64 \%$ of the cases.
} 
are provided for $\sigma=1$, which is an intermediate value of risk-aversion among those we explored (we return below to the issue of the appropriate value of the risk-aversion parameter).

In agreement with the model, $\hat{\beta}_{1 g}$ is positive and significant in almost every item for both sets of estimations. The results are thus very supportive of the effect of benefits in encouraging underreporting. Note that the few items in which the model performs badly, such as phones and trucks, are among those in which the assumption of effective monitoring of underreporting is suspect.

Also in agreement with the model, $\hat{\beta}_{2 g}$ is negative in almost every item. $\hat{\beta}_{2 g}$ is significant at $10 \%$ in most items in which it is negative, although significance levels are less impressive in equation (2) than in equation (1). When fixed effects are considered, significance is reduced in most items, except notably in concrete floor. Overall, the results are somewhat supportive of the effect of benefits in discouraging overreporting.

According to the model, for each item $g, \hat{\beta}_{1 g}$ should be indicative of what applicants who have this good believe is the weight given to it in the eligibility criterion, adjusted for the penalty expected for lying. In turn, $-\hat{\beta}_{2 g}$ should be indicative of what applicants who lack this good believe is the weight given to it in the eligibility criterion. With common beliefs, we would expect the weight adjusted for the lying penalty to be smaller than the weight of the good. In Table IV we have that $\hat{\beta}_{1 g}$ is larger than $\hat{\beta}_{2 g}$ in absolute value for almost every good. This suggests that the scale parameter in the definition of $\beta_{1 g}$ is smaller than the scale parameter in the definition of $\beta_{2 g}$. Recall that the variance of a logistic distribution is proportional to the scale parameter (see e.g. Train 2003). Thus, Table IV suggests that the variance of $\epsilon_{c a g}$ is smaller than the variance of $\epsilon_{\text {eag }}$ for almost every good; in other words, our independent variables do a better job explaining the cost of lying than the embarrassment cost.

Table $\mathrm{V}$ provides estimates of the relative weight of each good according to the estimated coefficients for equations (1) and (2). We assume that underreporters believe that the penalty for underreporting is proportional to the weight of each good. In terms of the discussion in the previous paragraph, the assumption here is that the variance of $\epsilon_{\text {cag }}$ is the same across goods, and 


\section{TABLE IV}

Estimated Coefficient of Utility Gains on Misreporting ${ }^{a}$

\begin{tabular}{|c|c|c|c|c|}
\hline \multirow[b]{3}{*}{ Good } & \multicolumn{2}{|c|}{ Underreporting Equation } & \multicolumn{2}{|c|}{ Overreporting Equation } \\
\hline & Without & Reg. Center & Without & Reg. Center \\
\hline & Fixed Effects & Fixed Effects & Fixed Effects & Fixed Effects \\
\hline \multirow[t]{2}{*}{ Concrete Floor } & 0.2276 & 0.2210 & -0.0654 & -0.1435 \\
\hline & $(0.0549)$ & $(0.0576)$ & $(0.0590)$ & $(0.0621)$ \\
\hline \multirow[t]{2}{*}{ Tap Water } & 0.2073 & 0.1447 & -0.0322 & -0.0876 \\
\hline & $(0.0536)$ & $(0.0566)$ & $(0.0591)$ & $(0.0668)$ \\
\hline \multirow[t]{2}{*}{ Toilet } & 0.1602 & 0.1528 & -0.1287 & -0.0959 \\
\hline & $(0.0486)$ & $(0.0526)$ & $(0.0614)$ & $(0.0663)$ \\
\hline \multirow[t]{2}{*}{ Gas Boiler } & 0.8035 & 0.5357 & -0.3022 & -0.2430 \\
\hline & $(0.2534)$ & $(0.2786)$ & $(0.1744)$ & $(0.1787)$ \\
\hline \multirow[t]{2}{*}{ Washing Machine } & 0.3853 & 0.1309 & -0.3672 & -0.0743 \\
\hline & $(0.1278)$ & $(0.1383)$ & $(0.0775)$ & $(0.0790)$ \\
\hline \multirow[t]{2}{*}{ Phone } & -0.1175 & -0.5016 & -0.3050 & -0.1027 \\
\hline & $(0.2547)$ & $(0.2947)$ & $(0.1554)$ & $(0.1587)$ \\
\hline \multirow[t]{2}{*}{ Car } & 1.5715 & 0.4476 & -0.3194 & -0.1887 \\
\hline & $(0.4904)$ & $(0.6140)$ & $(0.1988)$ & $(0.2025)$ \\
\hline \multirow[t]{2}{*}{ Truck } & -0.8698 & -1.2556 & 0.0437 & 0.1574 \\
\hline & $(0.3640)$ & $(0.4428)$ & $(0.1954)$ & $(0.1951)$ \\
\hline \multirow[t]{2}{*}{ Satellite TV } & 0.8467 & 0.0705 & 0.1800 & 0.0765 \\
\hline & $(0.2906)$ & $(0.4520)$ & $(0.1156)$ & $(0.1231)$ \\
\hline \multirow[t]{2}{*}{ Water Tank } & 0.5520 & 0.4628 & -0.2012 & -0.0931 \\
\hline & $(0.1663)$ & $(0.1835)$ & $(0.0917)$ & $(0.0952)$ \\
\hline \multirow[t]{2}{*}{ Refrigerator } & 0.5263 & 0.4305 & -0.2225 & -0.1055 \\
\hline & $(0.0721)$ & $(0.0760)$ & $(0.0591)$ & $(0.0628)$ \\
\hline \multirow[t]{2}{*}{ Gas Stove } & 0.5461 & 0.4049 & -0.3641 & -0.3478 \\
\hline & $(0.0561)$ & $(0.0603)$ & $(0.0507)$ & $(0.0545)$ \\
\hline \multirow[t]{2}{*}{ Video Recorder } & 0.7300 & 0.3341 & -0.3024 & -0.0470 \\
\hline & $(0.2791)$ & $(0.3247)$ & $(0.1287)$ & $(0.1306)$ \\
\hline
\end{tabular}

${ }^{a}$ With moderate risk-aversion $(\sigma=1)$. Standard errors in parenthesis; observations: 74034 . 


\section{TABLE V}

Weights of Goods in Program Participation ${ }^{a}$

\begin{tabular}{lcc}
\hline \hline \multirow{2}{*}{ Good } & \multicolumn{2}{c}{ Estimated Weights } \\
\cline { 2 - 3 } Concrete Floor & Under-Reporters & Over-Reporters \\
Tap Water & 0.035 & 0.025 \\
Toilet & 0.032 & 0.012 \\
Gas Boiler & 0.123 & 0.049 \\
Washing Machine & 0.059 & 0.116 \\
Phone & 0.000 & 0.141 \\
Car & 0.240 & 0.117 \\
Truck & 0.000 & 0.122 \\
Satellite TV & 0.129 & 0.000 \\
Water Tank & 0.084 & 0.000 \\
Refrigerator & 0.080 & 0.077 \\
Gas Stove & 0.083 & 0.085 \\
Video Recorder & 0.111 & 0.139 \\
\hline
\end{tabular}

${ }^{a}$ With moderate risk-aversion $(\sigma=1)$ and without fixed effects. Observations: 74034 .

similarly for $\epsilon_{e a g}$. Relative weights are calculated as

$$
\begin{aligned}
\text { weight of good } g \text { for under-reporters } & =\frac{\max \left\{0, \hat{\beta}_{1 g}\right\}}{\sum_{g^{\prime}} \max \left\{0, \hat{\beta}_{1 g^{\prime}}\right\}} \text {, and } \\
\text { weight of good } g \text { for over-reporters } & =\frac{\max \left\{0,-\hat{\beta}_{2 g}\right\}}{\sum_{g^{\prime}} \max \left\{0,-\hat{\beta}_{2 g^{\prime}}\right\}} .
\end{aligned}
$$

(We censor in each case the two estimated coefficients with incorrect signs from the point of view of the model.) Estimated relative weights for under and over-reporters are not far off for about half the items, in particular when compared with the true relative weights (obtained from administrative sources and omitted in the table). Note that, since applicants were unlikely to have access to the weights employed by the program, the assumption that applicants had common beliefs about the weights is only a useful simplification. 


\subsection{Effect of Program Benefits on Misreporting}

Next, we have estimated the effect of a marginal increase in per capita benefits of the program on the number of applicants who underreport as a percentage of those having the good, and on the number of applicants who overreport as a percentage of those lacking the good. For each item $g$ and for each applicant $a$ who has this good, the marginal increase in the probability of underreporting is equal to

$$
\frac{\partial \operatorname{Pr}\left(r_{a g}=0 \mid t_{a g}=1\right)}{\partial \Delta U\left(Y_{a}, B_{a}\right)} \times \frac{\partial \Delta U\left(Y_{a}, B_{a}\right)}{\partial B_{a}} .
$$

Thus, the marginal increase in the probability of underreporting for applicant $a$ can be estimated as

$$
\hat{\beta}_{1 g} f\left(\hat{\alpha}_{1 g}+\hat{\beta}_{1 g} \Delta U\left(Y_{a}, B_{a}\right)+\hat{\gamma}_{1 g} X_{a}\right) \times\left(Y_{a}+B_{a}\right)^{-\sigma},
$$

where $f(z) \equiv \exp (z) /(1+\exp (z))^{2}$.

We evaluate the expression above at the mean values of the exogenous variables for those having the good, and multiply this value by one hundred to obtain the marginal effect of the program benefits on underreporting. The marginal effect on overreporting is calculated similarly. (Note that, consistently with Table I, we define underreporting of good $g$ as the number of applicants who underreport as a percentage of the number of applicants who have this good, and define overreporting similarly.)

Table VI displays the results for four values of the risk-aversion coefficient. The significance levels are those of the estimated coefficient of $\Delta U\left(Y_{a}, B_{a}\right)$. In terms of fitting the signs predicted by the model and in terms of significance, the intermediate value of risk-aversion $(\sigma=1)$ does better than the high value $(\sigma=2)$ for both underreporting and overreporting, and does better than the low values $(\sigma=1 / 2$ and $\sigma=0)$ for overreporting and at least comparably for underreporting. ${ }^{13}$ If we are concerned about the use of expenditure per capita in the calculation of the utility gain, Table VI is reassuring: the results obtained measuring the utility gain as the cash benefit from the program $(\sigma=$

\footnotetext{
${ }^{13}$ Consumption studies, such as that of Banks et al. (2001) in the UK, estimate the coefficient of relative risk-aversion in around 2. With a different methodology, experimental studies both in the lab (Holt and Laury 2002) and in the field (Tanaka, Camerer and Nguyen 2006) favor estimates of around $1 / 2$.
} 
TABLE VI

Marginal Effect of Per Capita Benefits on Misreporting ${ }^{a}$

\begin{tabular}{|c|c|c|c|c|}
\hline \multirow[b]{3}{*}{ Good } & \multicolumn{2}{|c|}{ Risk Neutrality $(\sigma=0)$} & \multicolumn{2}{|c|}{ Low Risk Aversion $(\sigma=1 / 2)$} \\
\hline & Effect on & Effect on & Effect on & Effect on \\
\hline & Underreport & Overreport & Underreport & Overreport \\
\hline Concrete Floor & $0.0089^{* * *}$ & -0.0055 & $0.0193^{* * *}$ & -0.0085 \\
\hline Tap Water & 0.0025 & 0.0068 & $0.0091^{* *}$ & 0.0089 \\
\hline Toilet & 0.0006 & -0.0047 & 0.0050 & -0.0131 \\
\hline Gas Boiler & $0.0304^{* *}$ & -0.0008 & $0.0704^{* * *}$ & $-0.0018^{*}$ \\
\hline Washing Machine & $0.0294^{* * *}$ & $-0.0044^{* * *}$ & $0.0633^{* * *}$ & $-0.0110^{* * *}$ \\
\hline Phone & 0.0025 & $-0.0010^{*}$ & -0.0016 & $-0.0027^{* *}$ \\
\hline Car & $0.0546^{* * *}$ & $-0.0011^{* *}$ & $0.1154^{* * *}$ & $-0.0023^{* *}$ \\
\hline Truck & -0.0150 & 0.0002 & $-0.0549^{* *}$ & -0.0001 \\
\hline Cable/Satellite TV & 0.0115 & 0.0007 & 0.0463 & 0.0020 \\
\hline Water Tank & $0.0307^{* * *}$ & -0.0012 & $0.0685^{* * *}$ & $-0.0034^{*}$ \\
\hline Refrigerator & $0.0354^{* * *}$ & -0.0025 & $0.0788^{* * *}$ & $-0.0078^{*}$ \\
\hline Gas Stove & $0.0253^{* * *}$ & $-0.0163^{* * *}$ & $0.0561^{* * *}$ & $-0.0356^{* * *}$ \\
\hline \multirow[t]{3}{*}{ VCR } & 0.0134 & $-0.0014^{* *}$ & $0.0416^{*}$ & $-0.0035^{* *}$ \\
\hline & \multicolumn{2}{|c|}{ Mod. Risk Aversion $(\sigma=1)$} & \multicolumn{2}{|c|}{ High Risk Aversion $(\sigma=2)$} \\
\hline & Effect on & Effect on & $\begin{array}{c}\text { Effect on } \\
\text { Undrrenort }\end{array}$ & Effect on \\
\hline $\begin{array}{l}\text { Good } \\
\text { Concrete Floor }\end{array}$ & $\begin{array}{l}\text { Underreport } \\
0.0076^{* * *}\end{array}$ & $\begin{array}{c}\text { Overreport } \\
-0.0037\end{array}$ & $\begin{array}{l}\text { Underreport } \\
-0.0001\end{array}$ & $\frac{\text { Overreport }}{0.0000}$ \\
\hline Tap Water & $0.0068^{* * *}$ & -0.0020 & 0.0001 & -0.0001 \\
\hline Toilet & $0.0062^{* * *}$ & $-0.0089^{* *}$ & $0.0002^{* *}$ & 0.0000 \\
\hline Gas Boiler & $0.0386^{* * *}$ & $-0.0008^{*}$ & $0.0233^{* * *}$ & 0.0000 \\
\hline Washing Machine & $0.0255^{* * *}$ & $-0.0055^{* * *}$ & 0.0002 & $0.0001^{* *}$ \\
\hline Phone & -0.0056 & $-0.0010 * *$ & -0.0023 & 0.0000 \\
\hline Car & $0.0552^{* * *}$ & -0.0006 & $0.0242^{* *}$ & 0.0000 \\
\hline Truck & $-0.0298^{* *}$ & 0.0001 & -0.0031 & 0.0000 \\
\hline Cable/Satellite TV & $0.0435^{* * *}$ & 0.0008 & $0.0552^{* * *}$ & 0.0000 \\
\hline Water Tank & $0.0356^{* * *}$ & $-0.0019^{* *}$ & $0.0123^{* *}$ & 0.0000 \\
\hline Refrigerator & $0.0326^{* * *}$ & $-0.0067^{* * *}$ & -0.0001 & -0.0002 \\
\hline Gas Stove & $0.0266^{* * *}$ & $-0.0213^{* * *}$ & $0.0008^{* * *}$ & $-0.0022^{* * *}$ \\
\hline VCR & $0.0293^{*}$ & $-0.0015^{* *}$ & $0.0225^{* * *}$ & 0.0000 \\
\hline
\end{tabular}

${ }^{a}$ Marginal effects on probability of misreporting multiplied by 100. Estimation without fixed effects. Observations: 74034.

* significant at $10 \%$; ** significant at $5 \%$; ** significant at $1 \%$. 
0) are similar in sign and magnitude to those obtained for other assumptions on relative risk-aversion.

Using the estimates for $\sigma=1$ in Table VI, we have that increasing in 40 pesos (US\$ 3.63) the per capita benefits from the program (that is, roughly speaking, increasing the benefits in 50\%) would increase underreporting on cars, satellite TV, gas boilers, water tanks and refrigerators in between $1.3 \%$ and $2.2 \%$, and would reduce overreporting in gas stoves, toilets, refrigerators and washing machines in between $0.22 \%$ and $0.85 \%$.

\subsection{Effects of Education and Gender on Misreporting}

Of the independent variables other than $\Delta U\left(Y_{a}, B_{a}\right)$, education is of particular interest. If overreporting is simply or mostly the result of confusion, we would expect more educated applicants to overreport less frequently. On the other hand, if overreporting is at least in part the result of social embarrassment, we could expect more educated applicants to overreport more frequently than others. ${ }^{14}$

The marginal effects of education on misreporting are described in Table VII. The effect on underreporting is calculated as one hundred times

$$
\hat{\beta}_{1 g s} f\left(\hat{\alpha}_{1 g}+\hat{\beta}_{1 g} \Delta U\left(Y_{a}, B_{a}\right)+\hat{\gamma}_{1 g} X_{a}\right),
$$

evaluated at the mean values of the exogenous variables for those having the good, where $\hat{\beta}_{1 g s}$ is the estimated coefficient of school years in equation (1), and the other terms are as defined above. The effect on overreporting is calculated similarly.

The results come squarely in favor of the embarrassment hypothesis. In almost every item, education significantly increases the probability of overreporting. The effect is stronger for goods whose absence is more likely to be embarrassing, including toilets, concrete floor and tap water. ${ }^{15}$

\footnotetext{
${ }^{14}$ In the literature on voter turnout, for instance, the empirical fact that more educated people tend to vote more often is interpreted as a result of more educated people being better integrated in society and thus more susceptible to social pressure (Blais 2000).

${ }^{15} \mathrm{~A}$ potential criticism of these results is that individuals who overreported with respect to some goods may also be inclined to overreport with respect to years of education. We have found, however, that overreporting is more common in goods that most households have. Since most applicants have very few years of education, having little education is unlikely to be embarrassing.
} 
TABLE VII

Effects of Educhtion and Gender on Misreporting

\begin{tabular}{lcclll}
\hline \hline \multirow{2}{*}{ Good } & \multicolumn{2}{c}{ Effect of Education ${ }^{a}$ on } & & \multicolumn{2}{c}{ Effect of Gender ${ }^{b}$ on } \\
\cline { 2 - 3 } \cline { 5 - 6 } Concrete Floor & Underreport & Overreport & & Underreport & Overreport \\
\hline Tap Water & $-0.5493^{* * *}$ & $1.1765^{* * *}$ & & $2.0514^{* * *}$ & $-3.8949^{* * *}$ \\
Toilet & $-0.3259^{* * *}$ & $0.7088^{* * *}$ & & $2.7901^{* * *}$ & $-4.9492^{* * *}$ \\
Gas Boiler & $-0.7411^{* *}$ & $1.1539^{* * *}$ & & $3.1347^{* * *}$ & $-5.8000^{* * *}$ \\
Washing Machine & $0.6396^{* * *}$ & $0.1243^{* * *}$ & & -2.9654 & 0.0014 \\
Phone & -0.1050 & $0.0599^{* * *}$ & & 6.0261 & -0.341 \\
Car & 0.0005 & $0.0402^{* * *}$ & & $8.4165^{* *}$ & 0.0223 \\
Truck & 0.2439 & $0.0187^{* *}$ & & $9.7598^{* * *}$ & 0.0163 \\
Satellite TV & 0.2743 & $0.0386^{* * *}$ & & -2.0582 & 0.1664 \\
Water Tank & $-0.9232^{* * *}$ & $0.2761^{* * *}$ & & 3.1493 & 0.3662 \\
Refrigerator & $0.2068^{*}$ & $0.4351^{* * *}$ & & $3.6416^{* *}$ & $-2.0754^{* * *}$ \\
Gas Stove & $-0.2940^{* * *}$ & $1.0683^{* * *}$ & & $4.1881^{* * *}$ & $-5.0649^{* * *}$ \\
Video Recorder & $0.4468^{*}$ & -0.0231 & & -3.2651 & 0.3235 \\
\hline
\end{tabular}

${ }^{a}$ Marginal effect of years of education on probability of misreporting multiplied by 100 . ${ }^{b}$ Effect of a male rather than a female applicant on probability of misreporting multiplied by 100. Estimations with moderate risk-aversion $(\sigma=1)$ and without fixed effects. Observations: $74034 .{ }^{*}$ significant at $10 \%$; ${ }^{*}$ significant at $5 \% ;{ }^{* *}$ significant at $1 \%$.

Finally, we take a look at the effect of gender on misreporting. Since most of the applicants are women, and benefits from the program accrue to the mother of the household, our sample of male applicants is hardly representative. Undaunted, we proceed to calculate the difference in the behavior of male and female applicants with regard to reporting. The effect of gender on the percentage of misreporting is described in Table VII. Male applicants are significantly more likely to underreport and less likely to overreport in "status" goods and in durable goods, and (curiously) they are also significantly more likely to underreport in cars and trucks. ${ }^{16}$

\footnotetext{
${ }^{16}$ Evidence on gender differences in preferences is discussed by Eckel and Grossman (2003) and by Croson and Gneezy (2004). Croson and Gneezy (2004) note that research from psychology suggests that men are more overconfident than women, and that women are more sensitive to social cues in determining appropriate behavior. This seems to favor the interpretation of the evidence on overreporting as the result of embarrassment rather than wrong beliefs.
} 
TABLe VIII

Probability of Costly Lying and Embarrassment ${ }^{a}$

\begin{tabular}{lccccc}
\hline \hline & \multicolumn{2}{c}{ Probability of } & & \multicolumn{2}{c}{ Probability of } \\
& \multicolumn{2}{c}{ Costly Lying (\%) } & & Costly Embarrassment (\%) \\
\cline { 2 - 3 } \cline { 5 - 6 } Gedian & Highest & & Median & Highest \\
Cood & Applicant & $25 \%$ & & Applicant & $25 \%$ \\
\hline Tancrete Floor & 87.02 & 89.09 & & 25.54 & 28.75 \\
Toilet & 87.54 & 88.81 & & 31.87 & 34.07 \\
Gas Boiler & 84.54 & 86.57 & & 39.74 & 43.67 \\
Washing Machine & 31.91 & 39.85 & & 1.09 & 1.45 \\
Phone & 55.68 & 60.13 & & 5.90 & 9.91 \\
Car & 29.65 & 31.81 & & 1.24 & 2.05 \\
Truck & 24.34 & 32.79 & & 0.79 & 1.12 \\
Satellite TV & 14.43 & 20.42 & & 0.50 & 0.79 \\
Water Tank & 33.48 & 38.19 & & 1.12 & 2.38 \\
Refrigerator & 47.42 & 52.42 & & 3.78 & 4.97 \\
Gas Stove & 67.74 & 74.09 & & 12.37 & 14.70 \\
Video Recorder & 79.18 & 86.94 & & 28.73 & 37.62 \\
\cline { 1 - 2 } & 24.08 & 30.95 & & 2.04 & 2.88 \\
\hline
\end{tabular}

${ }^{a}$ With moderate risk-aversion $(\sigma=1)$ and without fixed effects. Observations: 74034 .

\subsection{The Costs of Lying and Embarrassment}

According to our model, the utility cost of lying about good $g$ for applicant $a$ if the applicant has this good is

$$
c_{a g}=\alpha_{c g}+\gamma_{c g} X_{a}+\epsilon_{c a g}=s_{1 g}\left(-\alpha_{1 g}-\gamma_{1 g} X_{a}+\epsilon_{1 a g}\right),
$$

where $\epsilon_{1 a g}$ has a standard logistic distribution. Thus, the ex ante probability that applicant $a$ has positive costs of lying (i.e. potentially deterring the applicant from underreporting) is

$$
\frac{1}{1+\exp \left(\alpha_{1 g}+\gamma_{1 g} X_{a}\right)} \text {. }
$$

Similarly, the ex ante probability that applicant $a$ has positive costs of embarrassment (i.e. potentially encouraging the applicant to overreporting) if the applicant does not have this good is

$$
\frac{1}{1+\exp \left(-\alpha_{2 g}-\gamma_{2 g} X_{a}\right)} \text {. }
$$


TABLE IX

Expected Cost of Lying and Embarrassment for Median Applicant ${ }^{a}$

\begin{tabular}{lcc}
\hline \hline Good & Cost of Lying & Cost of Embarrassment \\
\hline Concrete Floor & 2.04 & 0.29 \\
Tap Water & 2.08 & 0.38 \\
Toilet & 1.87 & 0.51 \\
Gas Boiler & 0.38 & 0.01 \\
Washing Machine & 0.81 & 0.06 \\
Phone & 0.35 & 0.01 \\
Car & 0.28 & 0.01 \\
Truck & 0.16 & 0.00 \\
Satellite TV & 0.41 & 0.01 \\
Water Tank & 0.64 & 0.04 \\
Refrigerator & 1.13 & 0.13 \\
Gas Stove & 1.57 & 0.34 \\
Video Recorder & 0.28 & 0.02 \\
\hline
\end{tabular}

${ }^{a}$ With moderate risk-aversion $(\sigma=1)$ and without fixed effects. Observations: 74034 .

We have evaluated these expressions using the estimated coefficients $\hat{\alpha}_{1 g}$, $\hat{\gamma}_{1 g}, \hat{\alpha}_{2 g}$ and $\hat{\gamma}_{2 g}$. Table VIII offers the median and the top 25 percentile for each sample. As the table shows, lying is likely to be costly in every item of the list, particularly with respect to goods that seem hard to hide or deny. Embarrassment is unlikely to be costly with the exception of a few items that may have a status value.

Finally, we can calculate the expected utility cost of lying for an applicant as

$$
\mathrm{E}\left(\max \left\{-\alpha_{1 g}-\gamma_{1 g} X_{a}+\epsilon_{1 a g}, 0\right\}\right) .
$$

Note that we omit the scale factor $s_{1 g}$ which we cannot identify from the data. This means that we can compare the utility cost of lying for different goods under the assumption that the scale factor is the same, but we cannot say anything about the magnitude of the cost of lying (we cannot calculate, for instance, a monetary estimate using compensating variations). Note also that we bound the cost from below by zero, i.e. we interpret a negative realization of $-\alpha_{1 g}-\gamma_{1 g} X_{a}+\epsilon_{1 a g}$ as meaning a zero cost of lying or no 
disincentive to lie. ${ }^{17}$ Solving the expectation we obtain that the expected cost of lying for an applicant that has good $g$ is

$$
-\alpha_{1 g}-\gamma_{1 g} X_{a}+\ln \left(1+\exp \left(\alpha_{1 g}+\gamma_{1 g} X_{a}\right)\right)
$$

Similarly, the expected cost of embarrassment for an applicant that does not have good $g$ is

$$
\alpha_{2 g}+\gamma_{2 g} X_{a}+\ln \left(1+\exp \left(-\alpha_{2 g}-\gamma_{2 g} X_{a}\right)\right)
$$

We have evaluated these expressions using the estimated coefficients $\hat{\alpha}_{1 g}$, $\hat{\gamma}_{1 g}, \hat{\alpha}_{2 g}$ and $\hat{\gamma}_{2 g}$. Table IX offers the median for each sample. We find that lying is somewhat costlier with respect to household characteristics and certain durable goods, and that embarrassment is a lot costlier for some of those household characteristics than for any other item.

\subsection{Was There a Penalty for Underreporting?}

We may ask if there was a penalty for underreporting after the household visit, beyond recalculating the score of a household to determine whether the household was eligible into the program. Of our sample of 74,034 initially eligible households, 64,842 households eventually became beneficiaries. Table $\mathrm{X}$ details the incidence of underreporting in households that did not become beneficiaries and in households that became beneficiaries. Given the high incidence of underreporting in the households that became beneficiaries in the end, we seriously doubt that there was any penalty for underreporting per se.

We also look at the sample of households who should have been declared eligible after the verification visit according to the program eligibility criterion, and compare the percentage of those who actually became program beneficiaries by whether they underreported or not. Of those who did not underreport any characteristics, 99 percent eventually became beneficiaries. Of those who do underreport, only 95 percent eventually became beneficiaries.

\footnotetext{
${ }^{17}$ It is simple to check that the likelihood function associated with equation (1) is the same whether we assume that $\epsilon_{1 a g}$ has a standard logistic distribution or that $\epsilon_{1 a g}$ has a density identical to the standard logistic density for $\epsilon_{1 a g} \geq \alpha_{1 g}+\gamma_{1 g} X_{a}$ and a point mass at $\epsilon_{1 a g}=\alpha_{1 g}+\gamma_{1 g} X_{a}$, as long as $\beta_{1 g}>0$.
} 
TABLE X

Underreporting and Final Status of Verified Households

\begin{tabular}{|c|c|c|c|c|c|c|}
\hline \multirow[b]{2}{*}{ Good } & \multicolumn{3}{|c|}{ Did Not Become Beneficiaries } & \multicolumn{3}{|c|}{ Became Beneficiaries } \\
\hline & Obs. & Mean & Std. Dev. & Obs. & Mean & Std. Dev. \\
\hline Concrete Floor & 8521 & 0.20 & 0.40 & 39045 & 0.13 & 0.34 \\
\hline Tap Water & 8045 & 0.16 & 0.37 & 43977 & 0.13 & 0.34 \\
\hline Toilet & 8526 & 0.18 & 0.39 & 45575 & 0.16 & 0.37 \\
\hline Gas Boiler & 1290 & 0.82 & 0.38 & 1093 & 0.64 & 0.48 \\
\hline Washing Machine & 2465 & 0.71 & 0.46 & 3818 & 0.42 & 0.49 \\
\hline Phone & 1169 & 0.82 & 0.38 & 788 & 0.59 & 0.49 \\
\hline Car & 752 & 0.91 & 0.28 & 384 & 0.67 & 0.47 \\
\hline Truck & 690 & 0.90 & 0.29 & 442 & 0.68 & 0.47 \\
\hline Satellite TV & 788 & 0.89 & 0.32 & 929 & 0.61 & 0.49 \\
\hline Water Tank & 1929 & 0.70 & 0.46 & 1902 & 0.46 & 0.50 \\
\hline Refrigerator & 6925 & 0.53 & 0.50 & 13103 & 0.29 & 0.45 \\
\hline Gas Stove & 8610 & 0.40 & 0.49 & 27201 & 0.19 & 0.40 \\
\hline Video Recorder & 1293 & 0.91 & 0.29 & 1114 & 0.67 & 0.47 \\
\hline
\end{tabular}

Observations: 74034. Source: ENCASURB.

While this might imply there was at least a minimum penalty to underreporting, we cannot separate this potential penalty from say, difference in take up rates between the two groups or other administrative issues. Given the very high rates of program participation of both groups, we conclude that there is little evidence of a rigorous or uniform penalty applied to underreporting.

\section{Conclusions}

How much do applicants to a social program misreport their "true" characteristics when they know this information will be used to determine participation in the program? How sensitive is misreporting to the program benefits? We find that underreporting is widespread. Overreporting is common in goods whose absence in a household is associated with poverty-precisely those goods that are likely to be given some weight in the methodology employed to determine participation in a poverty-alleviation program. Both underreporting and overreporting are sensitive to program benefits, more so in the case of underreporting. 
Though the effect of program benefits on misreporting is not large at the margin, it is significant in the case of underreporting for a variety of specifications. We believe this robust result is important because applicants were aware that underreporting could affect the probability of receiving the program (positively by increasing the probability of qualifying for a household visit and, perhaps, negatively by increasing the probability of being penalized for providing false information) but they were also aware that underreporting could not affect the benefits from participating in the program. Thus, if they were expected utility maximizers and did not suffer any disutility for lying per se, their decision to underreport or report truthfully should not have depended at all on the size of the benefits from the program, so long as these were positive. If we stick with the expected utility maximization hypothesis, we must conclude that applicants dislike deception enough to forego some probability of participating in a program with large benefits rather than deceiving.

There is evidence that people deviate from single-mindedly pursuing what is best from the point of view of their individual material interests in a variety of circumstances: they vote even though they know they are not decisive, they give to charities and political organizations, they punish others at a cost to themselves when they believe they have been treated unfairly. We show that people also deviate from single-mindedly maximizing their individual material interests (or rather those of their family) in the setting of a face-to-face interview with a program official. They do so in a manner that is consistent with the existence of a disutility for deceiving others and, possibly, a disutility for reporting the lack of some goods whose possession is widespread among households of a similar social condition.

From the viewpoint of the design of the process of selection of beneficiaries for targeted social programs, our research brings good and bad news. Among the good news, underreporting is widespread but not overwhelming, except for a few goods. Among the bad news, overreporting is common for a few goods, which implies that self-reporting may lead to the exclusion of deserving households. There is a wide variation in the incidence of misreporting for different goods. Thus, applicants' reports can be useful in the context of the selection of beneficiaries as long as the weights assigned to different goods take into account the incidence of misreporting. 
The crux of the "poverty regression" methodology is the use of data on household characteristics which are presumably observable and are statistically correlated with income. Our research points out that using the applicants' reports with weights obtained from a poverty regression is limited by the extent and variance across goods of misreporting. Moreover, finding the optimal weights is complex because the incidence of misreporting will not be constant with changes in the targeting methodology. That is, the issue of determining the optimal weights is not purely statistical but involves a strategic component.

More generally, our work suggests that the design of social programs can be improved by taking into account current research on the actual behavior of individuals in contexts that combine economic incentives with ethical and social considerations. And vice versa, the evidence coming from social programs offers a window to understanding the behavior of individuals in those contexts. 


\section{References}

[1] Linda Babcock and George Loewenstein (1997) Explaining Bargaining Impasse: The Role of Self-Serving Biases, Journal of Economic Perspectives

[2] James Banks, Richard Blundell and Agar Brugiavini (2001) Risk Pooling, Precautionary Saving and Consumption Growth, Review of Economic Studies 68: 757-779.

[3] Jere Behrman, Piyali Sengupta and Petra Todd (2005) Progressing through PROGRESA: An Impact Assessment of a School Subsidy Experiment in Rural Mexico, Economic Development and Cultural Change 54: $237-275$.

[4] Timothy Besley and Stephen Coate (1992) Workfare versus Welfare: Incentive Arguments for Work Requirements in Poverty-Alleviation Programs, American Economic Review 82: 249-261.

[5] Timothy Besley and Stephen Coate (1995) The Design of Income Maintenance Programmes, Review of Economic Studies 62: 187-221.

[6] André Blais (2000) To Vote or Not to Vote? The Merits and Limits of Rational Choice Theory, Pittsburgh: University of Pittsburgh Press.

[7] Sissela Bok (1999) Lying: Moral Choice in Public and Private Life, 2nd edition, New York: Vintage Books.

[8] Ying Chen (2005) Perturbed Communication Games with Honest Senders and Naive Receivers, typescript.

[9] Vincent P. Crawford (2003) Lying for Strategic Advantage: Rational and Boundedly Rational Misrepresentation of Intentions, American Economic Review 93: 133-149.

[10] Rachel Croson (2005) Deception in Economics Experiments, in Caroline Gerschlager (ed.) Deception in Markets: An Economic Analysis, Palgrave Macmillan. 
[11] Rachel Croson and Uri Gneezy (2004) Gender Differences in Preferences, typescript.

[12] Janet Currie (2004) The Take-Up of Social Benefits, forthcoming in Alan Auerbach, David Card, and John Quigley (eds), Poverty, The Distribution of Income, and Public Policy, New York: Russell Sage.

[13] Catherine Eckel and Philip J. Grossman (1999) Differences in the Economic Decisions of Men and Women: Experimental Evidence, forthcoming in Charles Plott and Vernon Smith (eds.), Handbook of Experimental Results, New York: Elsevier.

[14] David Ettinger and Philippe Jehiel (2006) Toward a Theory of Deception, typescript.

[15] Paul Gertler (2004) Do Conditional Cash Transfers Improve Child Health? Evidence from PROGRESA's Control Randomized Experiment, American Economic Review 94: 336-341.

[16] Uri Gneezy (2005) Deception: The Role of Consequences, American Economic Review 95: 384-394.

[17] Charles A. Holt and Susan K. Laury (2002) Risk Aversion and Incentives, American Economic Review 92: 1644-1655.

[18] Navin Kartik, Marco Ottaviani and Francesco Squintani (2006) Credulity, Lies and Costly Talk, forthcoming in Journal of Economic Theory.

[19] Robert Moffitt (1983) An Economic Model of Welfare Stigma, American Economic Review 73: 1023-1035.

[20] Martin Ravallion (1996) Issues in Measuring and Modelling Poverty, Economic Journal 106: 1328-1343.

[21] Regina T. Riphahn (2001) Rational Poverty or Poor Rationality? The Take-up of Social Assistance Benefits, Review of Income and Wealth 47: 379-398. 
[22] Reglas de Operación del Programa Oportunidades de Desarrollo del Capital Humano para el Ejercicio Fiscal 2002, Diario Oficial de la Federación, May 8, 2002.

[23] T. Paul Schultz (2004) School Subsidies for the Poor: Evaluating the Mexican Progresa Poverty Program, Journal of Development Economics 74: 199-250.

[24] Tomomi Tanaka, Colin Camerer and Quang Nguyen (2006) Preferences, Poverty, and Politics: Experimental and Survey Data from Vietnam, typescript.

[25] Petra Todd and Kenneth J. Wolpin (2004) Using a Social Experiment to Validate a Behavioral Model of Child Schooling and Fertility: Assessing the Impact of a School Subsidy Program in Mexico, forthcoming in American Economic Review.

[26] Kenneth Train (2003) Discrete Choice Methods with Simulation, Cambridge: Cambridge University Press. 